\title{
OBSERVATORY PUBLICATIONS IN THE SMALL INSTITUTE LIBRARY
}

\author{
Anne M. Fishburn \\ Max Planck Institutes for Astrophysics and \\ Extraterrestrial Physics \\ Garching, FRG
}

\section{INTRODUCTION}

I can imagine that many of us here represent a small institute library, and we can only look with wonder and envy at the vast collections of the US Naval Observatory and other such large and long-established libraries. We have a library of approx. 10000 monographs, 13000 bound serial volumes, 200 current serial titles and a report/observatory publications collection which grows at the rate of about 650 items per annum. In addition we receive about $800-1000$ preprints a year. We have a staff of 2 and 2 halves. One of our part-time people deals almost exclusively with the ordering and distribution of our Extraterrestrial preprints, reports and reprints.

Observatory publications play an interesting and important role in the literature of astronomy, and constitute a not negligible part of even the smallest library's stock. Careful control is necessary, as only then can the material be exploited to the full. One may often have doubts as to its value, but we dare not venture any qualitative judgements! Our present and future readers must be able to find this material, and it is our duty to store it and make it readily available in our own libraries and, failing that, to provide the means for finding it elsewhere.

\section{NATURE OF LITERATURE}

One can observe a changing emphasis in the type of observatory publication, at least in the Western context. As more and more astronomers submit their papers direct to the journals there are fewer and fewer series produced by the institutes and observatories themselves, such as Annals, Bulletins, Rendiconti; and in their place is a growing mountain of preprints. In the Eastern European and Asian countries there still exist more of the home- produced series, no doubt because low budgets and unfavourable exchange rates limit journal subscriptions and publication charges. Another growth area is the production of "Newsletters" and "Bulletins" as new institutes and projects spring up.

Another dying breed is, or certainly ought to be, the Reprint series, which I consider quite unnecessary and wasteful of the earth's resources, not to mention the institute of origin's budget. We send out a twice-yearly list of reprints available, and these are distributed while stocks last. In any case, most Western libraries have excellent photocopying and inter-library-loan facilities, and for other, less well-endowed libraries a postcard addressed to the author should suffice.

Preprints, on the other hand, are an important growth area. I have noticed that, even in the last few weeks, several new preprint series have arrived on the scene, mostly with bright eye-catching covers and - fortunately - sequential numeration. They are of particular importance to our readers as the interval between 
submission of a paper and its final publication in a journal is constantly increasing. Of course, many astronomers exchange their preprints privately among themselves, but the library should be seen to make itself the centre for receipt and display of information. Preprints do not present too much of an organisational problem to the small library, as by definition their life is of limited duration. If the preprint has not been published within a maximum of 2 years after its first appearance then it probably wasn't of any great importance anyway. It is our policy to discard preprints after about 2 years.

Report literature as produced by NASA, ESA etc is very important, and requires quite a lot of shelf space. At this point I would mention that we file these reports directly under their report numbers, i.e. NASA CP (No.) rather than under a conventional heading under the place. That is an example of a liberty which the small library can permit itself.

The nice thing about most of this type of literature is that it is free, and here we hit on the element of cooperation which plays such an important role. "Exchange", as already indicated by previous speakers, implies that there are two partners. If we are to receive preprints from Observatory $X$ then we should of course be prepared to send them ours in return. This is, I think, of particular importance to the non-Western libraries, and we should really try to foster these exchange links, despite attempts in all our institutes to economise on postage and production costs.

\section{PRACTICES}

We need to know what we have in our own library and it is also useful to know what other libraries have. This calls for a certain uniformity in cataloguing and establishing headings, at least for the production of union lists, though I think a certain degree of flexibility and pragmatism at a local level can be entertained, for instance, in the use of the vernacular rather than the internationally preferred English version of a town or institute. The smaller library, without the burden of extended responsibility which inevitably falls on the larger ones, is rather fortunate in being able to exercise a certain amount of freedom, some may call it illogicallity. We can keep separate files, and have physically separate shelving sequences for preprints, annual reports and the rest, we can decide arbitrarily which headings we establish, putting our users' interests before those of internationally recognised cataloguing rules, but only within our own house. As soon as we decide to cooperate in some scheme, such as Union List of Astronomy Serials, then we have to conform to those rules. In this way we may find ourselves with one set of rules for our readers and another set to follow when contributing to some union list. This would cause some extra work perhaps, but I feel that our first responsibility should be to our own readers.

Most observatory publications are fairly flimsy documents, and some means of protection is required in order to store them adequately. Opinions may vary on binding policy. We do not bind any observatory publications series, partly for reasons of economy, and partly because of incomplete runs. We use pamphlet boxes of A4 and A5 size, and interlocking cardboard drawers (A4 size). 


\section{USE}

The use made of this literature is often difficult to assess, especially in openaccess libraries open round the clock. Inevitably, the day after you have consigned to the cellar (if you are lucky enough to have one) some ancient series, your director will come along and ask for it urgently. I know of a certain observatory mountain library, which shall remain nameless, where the secretary responsible for looking after the library was using techniques worthy of Spycatcher or James Bond. Human hairs - her own - were intertwined with the ribbons tied round the boards enclosing the documents, and were still there on inspection weeks later, thus proving that no-one ever read the old stuff, which was only gathering dust and taking up valuable shelf space! No doubt the hairs are still there years later. It is often hard, faced with ever decreasing shelf-space, to justify our custodial function, but in the case of observatory publications, particularly the older material of historical value, I think we may have to take this function seriously, but with discrimination. We should not be afraid to discard old or incomplete series when we know with certainty of another accessible location with a complete set.

I should like to conclude with one or two random comments. The bibliographical control of this literature is most important, and Astronomy and Astrophy,sics Abstracts is still our main tool, so we should ensure that the editors in Heidelberg receive copies of everything. Librarians ought also to be able to exert some influence within their institute on the format and style of the publications produced. Very often one is frustrated, faced with some Newsletter or Bulletin, by not being able to find even such elementary and necessary information such as the place or complete name of the issuing institute or observatory. 